\title{
Risk Factors of Empyema in Children in Suzhou, China
}

\section{Lijun Li}

Soochow University Affiliated Children's Hospital

\section{Wen-jing Gu}

Soochow University Affiliated Children's Hospital

\section{Yin-yin Wu}

Soochow University Affiliated Children's Hospital

Zheng-rong Chen

Soochow University Affiliated Children's Hospital

Wei Ji ( $\sim$ szdxjiwei@163.com )

Soochow University Affiliated Children's Hospital

\section{Research}

Keywords: uncomplex parapneumonic effusion, empyema, risk factors, children

Posted Date: January 8th, 2021

DOl: https://doi.org/10.21203/rs.3.rs-139966/v1

License: (c) (i) This work is licensed under a Creative Commons Attribution 4.0 International License. Read Full License 


\section{Abstract}

Background

Respiratory tract infection is the most common disease in children, and pneumonia is the main disease. Pleural effusion is a common complication of pneumonia. Data show that up to $57 \%$ of hospitalized pneumonia patients have pleural effusion ${ }^{[1]}$. The parapneumonic pleural effusion (PPE) was divided into three categories: uncomplicated parapneumonic effusion (uppe), complex parapneumonic pleural effusion (CPPE) and parapneumonic empyema (PE)

${ }^{[2]}$.Empyema is a kind of respiratory tract infectious disease with dangerous condition, rapid development and high mortality. Improper treatment can also develop into chronic empyema, and severe complications such as bronchopleural fistula, lung abscess and heart failure may occur. Therefore, timely identification of empyema, active and effective treatment and necessary invasive operation are very important to slow down the disease and reduce the mortality rate.

\section{Methods}

To analyzed the data of children with parapneumonic pleural effusion who were hospitalized in respiratory department of our hospital from January 2010 to December 2018. According to the results of pleural effusion, according to the light classification standard, they were divided into uncomplex parapneumonic effusion (UPPE group) and empyema group (PE group),Logistic regression was used to analyze the risk factors of empyema in children, and receiver operating characteristic (ROC) curve was drawn.

\section{Results}

A total of 63 children were included in the study, including 20 cases in UPPE group and 43 cases in PE group. Univariate analysis showed that children in PE group were younger than those in UPPE group [2.8 $(1.1,5.83)$ vs. $6.54(2.94,9.0), P<0.05]$, clinical manifestations were more prone to shortness of breath $(60.46 \%$ vs. $8.961, \mathrm{P}<0.05)$, wheezing (32.55\% vs. $5 \%, \mathrm{P}<0.05)$, and C-reactive protein (CRP) in laboratory examination was higher [114.76 (54.19160.94) vs. $49.79(23.68,84.48), P<0.05]$; In cellular immunity, CD3 + was lower $(55.31 \pm 14.15$ vs. $65.76 \pm 11.43, P<0.05)$, CD3 + CD4 + was lower $(27.32 \pm 9.58$ vs. $34.77 \pm 7.99, \mathrm{P}<0.05), \mathrm{CD} 3-\mathrm{CD} 19+$ was higher $(31.61 \pm 13.24$ vs. $21.98 \pm 9.63, \mathrm{P}<0.05)$, and more susceptible to bacterial infection $(44.18 \%$ vs. $10 \%, \mathrm{P}<$ 0.01).Multivariate logistic regression analysis showed that shortness of breath (or $=5.099,95 \% \mathrm{Cl}: 1.309-19.866$ ) and elevated CRP (or $=1.013,95 \% \mathrm{Cl}$ : 1.001 1.026) were independent risk factors for empyema. The area under the ROC curve (AUC) of logistic regression model was 0.707 and 0.716 , respectively, with moderate diagnostic accuracy.

\section{Conclusions}

The children with parapneumonic pleural effusion with shortness of breath and CRP $>89.41 \mathrm{mg} / \mathrm{l}$ should be aware of empyema.

\section{Introduction}

Respiratory tract infection is the most common disease in children, and pneumonia is the main disease.Pleural effusion is a common complication of pneumonia. Data show that up to $57 \%$ of hospitalized pneumonia patients have pleural effusion ${ }^{[1]}$. Pleural effusion caused by exudative pneumonia, lung abscess and atelectasis is called parapneumonic pleural effusion (PPE),PPE was divided into three categories: uncomplicated parapneumonic effusion (uppe), complex parapneumonic pleural effusion (CPPE) and parapneumonic empyema (PE) ${ }^{[2]}$. The incidence of empyema is very small, about $4 \%-5 \%$. However, empyema is a kind of respiratory tract infectious disease with dangerous condition, rapid development and high mortality. Improper treatment can also develop into chronic empyema, and severe complications such as bronchopleural fistula, lung abscess and heart failure may occur.Therefore, timely identification of empyema, active and effective treatment and necessary invasive operation are very important to slow down the disease and reduce the mortality rate.

This study retrospectively analyzed the clinical data of children with PE and uppe, and explored the risk factors of empyema.

There were 43 cases of PE, 20 cases of uppe and 2 cases of CPPE.The data of 43 cases of PE and 20 cases of uppe were analyzed retrospectively.

\section{Materials And Methods General information}

Methods: from January 2010 to December 2018, children hospitalized in the respiratory department of our hospital due to parapneumonic pleural effusion and pleural effusion puncture were selected as the research objects, and the retrospective analysis was conducted.

Inclusion criteria: 1. Meet the diagnostic criteria of pneumonia in the guidelines for diagnosis and treatment of community acquired pneumonia specified by the society of respiratory diseases, Chinese Medical Association; 2. Diagnosed with pleural effusion by imaging examination (one of chest ultrasound, $X$-ray film or CT); 3. Aged from 1 month to 18 years old; 4. Pleural effusion detection after admission; 5. Diagnosis of PE and CPPE children; 2;6. Exclude patients with potential immune deficiency, malignant tumor, chest trauma, rheumatic immunity, etc.

Grouping criteria: according to light standard, the patients were divided into simple pleural effusion group (uppe group) and empyema group (PE group). Methods 
1.Imaging examination (chest ultrasound, X-ray plain film or CT) was performed before or after admission.

2. Specimen collection and laboratory testing

2.1 Blood collection and laboratory test: peripheral venous blood was taken on the day of admission for examination, including total white blood cell (WBC), proportion of neutrophils ( $\mathrm{n} \%)$, platelet (PLT), C-reactive protein (CRP), serum lactate dehydrogenase (LDH), complement (C3, C4), and serum

Immunoglobulin (IGA, IgG, IgM) content and lymphocyte immune subsets [CD3 +, CD3 + CD 4 +, CD3 + CD8 +, CD4 / CD8, cd3-cd19 +, CD19 + CD23 +, cd3-cd $(16+56+)]$.

2.2Collection and laboratory test of nasopharynx partial secretion: within 24 hours after admission, the children were collected with sterile negative pressure sputum suction method, and bacterial culture and related pathogen detection were carried out,Such as: respiratory syncytial virus, adenovirus, influenza virus A, influenza virus B, parainfluenza virus 1 , parainfluenza virus 2, parainfluenza virus 3 , rhinovirus, metapneumovirus, bocavirus, Mycoplasma pneumoniae, Chlamydia pneumoniae.

2.3 Collection and laboratory test of bronchoalveolar lavage fluid (BALF): bronchoscopy and alveolar lavage were performed according to the needs of the disease. BALF was collected and sent to multiple etiological tests (the test items were the same as those of nasopharynx secretion).

2.4 Collection of pleural effusion: after admission, according to the patient's condition, standard aseptic operation, pleural puncture was carried out, and 15 $20 \mathrm{ml}$ pleural effusion was transferred into test tube and blood culture bottle, and sent for examination immediately.

2.4.1 The examination of pleural effusion: first, fresh pleural puncture fluid was taken to observe its appearance and solidity, and then put it on the counting plate of the cistern. The number of white blood cells, total cells and the percentage of mesothelial cells, lymphocytes and neutrophils were counted under a high-power microscope. The qualitative test of mucin was performed by glacial acetic acid method. The above operations were strictly in accordance with the operation procedures.

2.4.2 The biochemical examination of pleural effusion: the pleural puncture pus was centrifuged at $3000 \mathrm{R} / \mathrm{min}$ for 5 min, and the supernatant was taken for biochemical detection of pleural effusion. Adenosine deaminase (ADA) was determined by peroxidase method, lactate dehydrogenase (LDH) was determined by IFCC method, total protein was determined by biuret method, and glucose was determined by hexokinase method. Hitachi 7180 automatic biochemical analyzer was used for detection.

2.4.3The pleural effusion bacterial culture: $10 \mu$ I pleural effusion samples were made into suspension, and the suspensions were inoculated in Columbia selective medium ( 1 blood plate) and Zhengzhou selective medium ( 1 chocolate agar plate) respectively, and cultured in $5 \% \mathrm{CO}_{2}$ incubator $\left(35{ }^{\circ} \mathrm{C}, 18 \sim 24 \mathrm{~h}\right.$ ). Bacteria were identified according to colony characteristics, Gram staining, microscopic observation and biochemical reaction,Bacterial colony was positive.Columbia agar is the product of British Oxoid company, Zhengzhou agar is the product of Zhengzhou Antu Bioengineering Co., Ltd.The specific operation and result determination were carried out according to the bacteriological test procedure of the specimen.

This study was approved by the hospital medical ethics committee (approval No.2020CS018),All the guardians of the children had informed consent.

\section{Statistical treatment}

Spss21.0 software package was used for statistical analysis. The data are in accordance with normal distributionT test was used to compare the two groups. The non-conforming normal scores were expressed by median and interquartile distance, and the comparison between the two groups was performed by Mann Whitney $\mathrm{U}$ test. The count data were expressed as percentage or rate. Fisher exact probability method was used for comparison between the two groups if $\mathrm{T}<1$ or $\mathrm{n}<40$; correction ( ${ }^{2}$ test was used if $1<\mathrm{T}<5$ and $\mathrm{N}>40$; and ( ${ }^{2}$ test was used if $\mathrm{t}>5$ and $\mathrm{n}>40$. The difference was statistically significant ( $\mathrm{P}<$ 0.05).Multivariate logistic regression analysis was made for the factors with $\mathrm{P}<0.05$ in univariate analysis, and ROC curve was drawn to evaluate the predictive ability of the regression model.

\section{Result}

\section{univariate analysis of general condition and empyema.}

In this study, 20 children with uppe and 43 children with PE were included.The median age of PE group was 2.8 years old, which was significantly lower than that of uppe group (6.54 years old). The difference between the two groups was statistically significant $(P<0.05)$. Children in $P E$ group were more prone to shortness of breath $\left(X^{2}=8.961, P<0.01\right)$ and wheezing $\left(X^{2}=5.715, P<0.05\right)$. There were no significant differences in gender, onset days, fever days, fluid infusion days and birth weight between the two groups $(P>0.05)$. The median CRP value of PE group was 114.76 mg/l, which was significantly higher than that of uppe group $(49.79 \mathrm{mg} / \mathrm{l}, \mathrm{P}<0.05)$. The levels of CD3 and CD3 + CD4 + in PE group were 55.31 \pm 14.15 and $27.32 \pm 9.58$, respectively, which were lower than $65.76 \pm 11.43$ and $34.77 \pm 7.91$ in Uppe group, with significant difference between groups $(P<0.05)$. The cd3-cd19+ of $P E$ group was $31.61 \pm 13.24$, which was higher than that of uppe group $(21.98 \pm 9.63)$, the difference was statistically significant $(P<0.05)$. There was no significant difference in WBC, $\mathrm{n} \%$, $\mathrm{PLT}$, $\mathrm{LDH}, \mathrm{C} 3, \mathrm{C} 4$, IgA, IgG, IgM, CD3 + CD8 +, CD4 / CD8, CD19 + CD23 +, CD3-CD (16 + 56) + between the two groups (all P>0.05), as shown in Tables 1 and 2.The bacterial infection rate in $\mathrm{PE}$ group was $44.18 \%$, which was significantly higher than that in Uppe group (10\%). The difference was statistically significant ( $\mathrm{P}<$ 0.01). The main pathogens detected in PE group were Streptococcus pneumoniae and Staphylococcus aureus, and the main pathogens in Uppe group were Mycoplasma pneumoniae, as shown in Table 3 and Table 4. There was no significant difference in lung imaging between the two groups, as shown in Table 5.Univariate analysis showed that age, shortness of breath, wheezing, CRP, CD3, CD3 + CD4 +, CD3-CD19 + were risk factors for empyema. 
Table 1

Comparison of clinical characteristics between uppe group and PE group

\begin{tabular}{|c|c|c|c|c|c|c|c|c|c|c|c|}
\hline group & $\begin{array}{l}\text { Number } \\
\text { of } \\
\text { cases }\end{array}$ & $\begin{array}{l}\text { Age } \\
\text { [age, m (P25 } \\
\text { p75)] }\end{array}$ & $\begin{array}{l}\text { Male / } \\
\text { female } \\
\text { (example) }\end{array}$ & $\begin{array}{l}\text { birth } \\
\text { weight } \\
(\mathrm{kg},)^{\prime}\end{array}$ & $\begin{array}{l}\text { Days of } \\
\text { onset at } \\
\text { admission } \\
\text { (d, ) }\end{array}$ & $\begin{array}{l}\text { Fever } \\
\text { days } \\
\text { before } \\
\text { admission } \\
\text { (d, ) }\end{array}$ & $\begin{array}{l}\text { Infusion } \\
\text { days } \\
\text { before } \\
\text { admission } \\
\text { (d, ) }\end{array}$ & $\begin{array}{l}\text { cough } \\
\text { [cases } \\
(\%)]\end{array}$ & $\begin{array}{l}\text { fever } \\
\text { [cases } \\
(\%)]\end{array}$ & $\begin{array}{l}\text { Wheezing } \\
\text { [cases } \\
(\%)]\end{array}$ & $\begin{array}{l}\text { Shortness } \\
\text { of breath } \\
\text { [cases } \\
(\%) \text { ] }\end{array}$ \\
\hline $\begin{array}{l}\text { Uppe } \\
\text { group }\end{array}$ & 20 & $6.54(2.94,9.00)$ & $14 / 6$ & $\begin{array}{l}3.44 \pm \\
0.40\end{array}$ & $\begin{array}{l}8.73 \pm \\
4.99\end{array}$ & $\begin{array}{l}7.15 \pm \\
4.09\end{array}$ & $\begin{array}{l}5.22 \pm \\
3.20\end{array}$ & $20(100)$ & $19(95)$ & $1(5)$ & $4(20)$ \\
\hline $\begin{array}{l}\text { PE } \\
\text { group }\end{array}$ & 43 & $2.8(1.1,5.83)$ & $19 / 24$ & $\begin{array}{l}3.41 \pm \\
0.42\end{array}$ & $\begin{array}{l}8.67 \pm \\
6.54\end{array}$ & $\begin{array}{l}6.45 \pm \\
4.70\end{array}$ & $\begin{array}{l}3.33 \pm \\
3.57\end{array}$ & $41(95.34)$ & 40(93.02) & $14(32.55)$ & $26(60.46)$ \\
\hline $\begin{array}{l}t / Z / \\
x^{2}\end{array}$ & & 5.724 & 3.647 & 0.076 & 0.05 & 0.316 & 2.29 & 0.961 & 0.09 & 5.715 & 8.961 \\
\hline $\begin{array}{l}P \\
\text { value }\end{array}$ & & 0.017 & 0.056 & 0.784 & 0.971 & 0.576 & 0.058 & 0.327 & 0.765 & 0.024 & $<0.01$ \\
\hline
\end{tabular}

Note: shortness of breath: infants $<2$ months, breathing $\geq 60$ times / min; $2 \sim 12$ months, breathing $\geq 60$ times / min; $1 \sim 5$ years old, breathing $\geq 40$ times / I breathing $\geq 30$ times / $\mathrm{min}$.

Table 2

Comparison of laboratory examination between uppe group and PE group

\begin{tabular}{|c|c|c|c|c|c|c|c|c|c|c|c|}
\hline group & $\begin{array}{l}\text { WBC } \\
\left(\times 10^{9} \cdot \mathrm{L}^{-1}\right)\end{array}$ & $\begin{array}{l}N \\
(\%)\end{array}$ & $\begin{array}{l}\text { PLT } \\
\left(\times 10^{9} \cdot \mathrm{L}^{-}\right. \\
\left.{ }^{1}\right)\end{array}$ & $\begin{array}{l}\text { CRP } \\
(\mathrm{mg} / \mathrm{L})\end{array}$ & $\begin{array}{l}\text { LDH } \\
(\mathrm{U} / \mathrm{L})\end{array}$ & $\begin{array}{l}\text { albumin } \\
\text { (g/L) }\end{array}$ & $\begin{array}{l}\text { C3 } \\
(g / L)\end{array}$ & $\begin{array}{l}\text { C4 } \\
(g / L)\end{array}$ & $\begin{array}{l}\lg A \\
(g / L)\end{array}$ & $\begin{array}{l}\lg G \\
(g / L)\end{array}$ & l! \\
\hline $\begin{array}{l}\text { Uppe } \\
\text { group }\end{array}$ & 10.98(8.87,19.25) & $\begin{array}{l}69.43 \\
\pm \\
17.42\end{array}$ & $\begin{array}{l}388.61 \\
\pm 149.68\end{array}$ & $49.79(23.68,81.48)$ & $\begin{array}{l}552.98 \\
\pm \\
300.94\end{array}$ & $\begin{array}{l}37.44 \pm \\
5.16\end{array}$ & $1.18(1.11,1.53)$ & $0.29(0.23,0.38)$ & $\begin{array}{l}1.47 \\
\pm \\
0.93\end{array}$ & $\begin{array}{l}11.25 \\
\pm 5.59\end{array}$ & $\begin{array}{l}1 \\
\pm \\
0\end{array}$ \\
\hline $\begin{array}{l}\text { PE } \\
\text { group }\end{array}$ & 18.87(7.86,29.23) & $\begin{array}{l}73.92 \\
\pm \\
13.28\end{array}$ & $\begin{array}{l}398.60 \\
\pm 220.22\end{array}$ & $114.76(54.19,160.94)$ & $\begin{array}{l}599.97 \\
\pm \\
309.81\end{array}$ & $\begin{array}{l}36.37 \pm \\
4.05\end{array}$ & $1.18(0.93,1.46)$ & $0.29(0.17,0.38)$ & $\begin{array}{l}1.07 \\
\pm \\
0.78\end{array}$ & $\begin{array}{l}10.16 \\
\pm 5.00\end{array}$ & $\begin{array}{l}1 \\
\pm \\
0\end{array}$ \\
\hline $\begin{array}{l}t / Z / \\
x^{2}\end{array}$ & 2.404 & 1.238 & 0.031 & 8.784 & 0.315 & 9.098 & 0.656 & 0.006 & 2.871 & 0.550 & 1 \\
\hline $\begin{array}{l}P \\
\text { value }\end{array}$ & 0.121 & 0.270 & 0.861 & $<0.01$ & 0.577 & 0.380 & 0.417 & 0.938 & 0.096 & 0.461 & 0 \\
\hline
\end{tabular}

\begin{tabular}{|c|c|c|c|c|c|c|c|}
\hline \multirow[t]{2}{*}{ group } & \multicolumn{7}{|c|}{ Lymphocyte subpopulations (\%, $\overline{\mathrm{x}} \pm \mathrm{s}$ ) } \\
\hline & CD3+ & CD3 + CD4+ & CD3 + CD8+ & CD4/CD8 & CD3-CD19+ & CD19 + CD23+ & CD3-CD $(16+56)+$ \\
\hline Uppe group & $65.76 \pm 11.43$ & $34.77 \pm 7.91$ & $25.5 \pm 6.01$ & $1.33 \pm 0.34$ & $21.98 \pm 9.63$ & $9.14 \pm 3.49$ & $10.36 \pm 7.61$ \\
\hline PE group & $55.31 \pm 14.15$ & $27.32 \pm 9.58$ & $23.55 \pm 10.90$ & $1.29 \pm 0.59$ & $31.61 \pm 13.24$ & $9.95 \pm 5.12$ & $11.08 \pm 7.98$ \\
\hline$t / \chi^{2}$ & 6.454 & 7.067 & 0.421 & 0.048 & 6.514 & 0.304 & 0.088 \\
\hline$P$ value & 0.014 & 0.011 & 0.52 & 0.828 & 0.014 & 0.586 & 0.768 \\
\hline
\end{tabular}


Detection of pathogens in Uppe group and PE group table

\begin{tabular}{|c|c|c|}
\hline pathogeny & Uppe group (cases) & $\begin{array}{l}\text { PE group } \\
\text { (cases) }\end{array}$ \\
\hline Streptococcus pneumoniae & 1 & 5 \\
\hline Staphylococcus aureus & 0 & 4 \\
\hline Rhinovirus & 0 & 1 \\
\hline Parainfluenza virus-3 & 1 & 0 \\
\hline Streptococcus pyogenes & 0 & 1 \\
\hline mycoplasma pneumoniae & 4 & 4 \\
\hline Rhinovirus & 0 & 1 \\
\hline Parainfluenza virus-3 & 1 & 0 \\
\hline Streptococcus pneumoniae + Mycoplasma pneumoniae & 0 & 2 \\
\hline Streptococcus pneumoniae + Mycoplasma pneumoniae + adenovirus & 0 & 1 \\
\hline Staphylococcus aureus + Mycoplasma pneumoniae & 0 & 1 \\
\hline Golden Globe + syncytial virus & 0 & 2 \\
\hline Staphylococcus aureus + rhinovirus & 0 & 1 \\
\hline Mycoplasma pneumoniae + Enterococcus faecium & 0 & 1 \\
\hline Mycoplasma pneumoniae + Staphylococcus hominis & 0 & 1 \\
\hline Mycoplasma pneumoniae + Haemophilus influenzae & 1 & 0 \\
\hline
\end{tabular}

Table 4

Comparison of pathogen detection between uppe group and PE group

\begin{tabular}{|llll|}
\hline group & \multicolumn{2}{l}{ Etiology [cases (\%)] } \\
\cline { 2 - 4 } & $\begin{array}{l}\text { bacterial infection } \\
\text { [cases (\%)] }\end{array}$ & $\begin{array}{l}\text { viral infection } \\
\text { [cases (\%)] }\end{array}$ & Mycoplasma pneumoniae infection [cases (\%)] \\
\hline Uppe group & $2(10.0)$ & $1(5.0)$ & $5(25.0)$ \\
\hline PE group & $19(44.18)$ & $5(11.62)$ & $10(23.25)$ \\
\hline t/ $\chi^{2}$ & 7.179 & 0.696 & 0.084 \\
\hline P value & $<0.01$ & 0.655 & 1.0 \\
\hline
\end{tabular}

Table 5

Comparison of lung imaging between uppe group and PE group

\begin{tabular}{|lllllll|}
\hline group & $\begin{array}{l}\text { Volume of pleural effusion } \\
(\mathbf{m m}, \overline{\mathbf{x}} \pm \mathbf{s})\end{array}$ & $\begin{array}{l}\text { Pulmonary consolidation } \\
\text { [cases }(\%)]\end{array}$ & $\begin{array}{l}\text { Lobar pneumonia } \\
\text { [cases }(\%)]\end{array}$ & $\begin{array}{l}\text { Atelectasis } \\
\text { [cases }(\%)]\end{array}$ & $\begin{array}{l}\text { pneumothorax } \\
\text { [cases }(\%)]\end{array}$ & $\begin{array}{l}\text { pulmonary abscess } \\
\text { [cases }(\%)]\end{array}$ \\
\hline Uppe group & $60.38 \pm 22.55$ & $10(50)$ & $7(35)$ & $11(55)$ & $6(30)$ & $2(10)$ \\
\hline PE group & $66.13 \pm 28.11$ & $25(58)$ & $8(18.60)$ & $20(46.51)$ & $17(39.53)$ \\
\hline t/ $\chi^{2}$ & 0.423 & 0.366 & 2.023 & 0.394 & 1.322 & 0.171 \\
\hline P value & 0.519 & 0.545 & 0.155 & 0.53 & 0.25 & 0.679 \\
\hline
\end{tabular}

\section{multivariate logistic regression analysis of related factors of empyema}

Age, shortness of breath, wheezing, CRP, CD3, CD3 + CD4 +, cd3-cd19+, bacterial infection were introduced into multivariate logistic regression analysis. It was found that higher CRP (or $=1.013,95 \% \mathrm{Cl}: 1.001 \sim 1.026$ ) and shortness of breath (or $=5.099,95 \% \mathrm{Cl}: 1.309 \sim 19.866$ ) were independent risk factors of empyema. See Table 6.The area under ROC curve (AUC) was $0.716,95 \% \mathrm{Cl}$ was $0.58-0.852, \mathrm{P}=0.01$, cutoff value was $89.41 \mathrm{mg} / \mathrm{L}$, sensitivity: $60.0 \%$, specificity: $82.4 \%$. The area under ROC curve (AUC) was $0.706,95 \% \mathrm{Cl}$ was $0.56-0.854, \mathrm{P}=0.014$. 
Table 6

Results of logistic regression analysis on the related factors of empyema formation

\begin{tabular}{|lllllll|}
\hline variable & $\boldsymbol{B}$ & S.E. & Wald & P value & Or value & $95 \%$ Cl \\
\hline CRP & 0.013 & 0.006 & 4.494 & 0.034 & 1.013 & $1.001 \sim 1.026$ \\
\cline { 1 - 4 } Shortness of breath & 1.629 & 0.694 & 5.511 & 0.019 & 5.099 & $1.309 \sim 19.866$ \\
\cline { 1 - 3 } & -0.985 & 0.623 & 2.501 & 0.114 & 0.373 & \\
\hline
\end{tabular}

\section{Discuss}

Pyothorax is a purulent infection in which pathogenic bacteria invade the pleura or lymphoid tissue directly or indirectly, and the purulent exudate accumulated in the pleural cavity [4].There are many reports that the incidence of empyema in children is increasing ${ }^{[5-6]}$.Empyema mostly develops from pneumonia.The pathological process of pleural effusion can be divided into three stages: exudative stage, fibrous purulent stage and organizing stage.The mortality of empyema can be as high as $15 \% \sim 20 \%{ }^{[7]}$. There is no uniform standard for the treatment of pleural effusion, and each stage of treatment focuses on different, which requires our clinicians to identify empyema in time, and strive to give timely and effective treatment in the shortest time.

The main clinical manifestations of parapneumonic pleural effusion were cough, fever and shortness of breath.Alveolar ventilation is usually strictly controlled by the central and peripheral chemoreceptors and lung receptors. The body can correct hypoxemia by increasing tidal volume and respiratory rate. Therefore, respiratory rate can indirectly reflect the situation of hypoxia. Foreign studies have reported that significantly increased respiratory rate is a significant independent risk factor for hypoxia ${ }^{[8]}$,Some studies ${ }^{\left[{ }^{9-11]}\right.}$ believe that shortness of breath is closely related to mechanical ventilation, ICU admission and mortality.In empyema, pathogens cause mesothelial cell death, which can release inflammatory factors such as interleukin-8 (IL-8), vascular endothelial growth factor (VEGF), monocyte chemoattractant protein-1 (MCP-1) and tumor necrosis factor - a (TNF - a) into the pleural cavity, resulting in more intense inflammatory reaction of pleura and lung injury, which seriously affects the ventilation function of lung, so it is necessary to accelerate the respiratory rate to compensate. The rate of shortness of breath in PE children was $60.46 \%$, which was significantly higher than that in Uppe children (20\%).In a retrospective study of 205 children with empyema ${ }^{[12]}, 82.4 \%$ of them had shortness of breath.In this study, shortness of breath was an independent risk factor for empyema.

In this study, CRP in PE group and uppe group were significantly increased, and the median CRP value of PE group was 114.76 mg/l, which was significantly higher than that of uppe group ( $49.79 \mathrm{mg} / \mathrm{l})$.CRP is a kind of acute phase reactive protein, mainly synthesized by the liver. In acute infection, the concentration of CRP rises rapidly, and the rising range is directly proportional to the degree of infection.Inflammatory stimulation after pulmonary parenchyma infection damages capillary epithelium and releases inflammatory cytokines, such as interleukin-6, interleukin-8, and TNF ${ }^{[13]}$, which increases capillary permeability, resulting in the exudation of CRP in blood vessels and the increase of CRP level in pleural effusion ${ }^{[14]}$. Domestic studies suggest that the higher the concentration of CRP in serum and pleural effusion, the greater the possibility of infectious pleural effusion ${ }^{[15]}$.Serum CRP has certain diagnostic value for complex pleural effusion. A prospective study of 1269 children with pleural effusion by Chalmers et al. ${ }^{[16]}$ showed that serum CRP > 100 mg / I was an independent risk factor for complex pleural effusion or empyema.In this study, logistic regression analysis also showed that CRP was an independent risk factor for empyema. The critical value of CRP was $89.41 \mathrm{mg} / \mathrm{L}$, and the sensitivity and specificity were $60.0 \%$ and $82.4 \%$ respectively.

In the pleural effusion examination, Mycoplasma pneumoniae accounted for 25\% (5 / 20 cases) in children with simple parapneumonia pleural effusion, while bacterial infection was the main pathogen in children with empyema, accounting for $44.18 \%$ ( 19 / 43 cases). It is reported that Streptococcus pneumoniae is the most common infectious pleural effusion in children ${ }^{[17]}$, while Mycoplasma pneumoniae infection is the main cause of pleural effusion in children ${ }^{[18]}$.In clinical practice, it can be detected by multiple etiological tests, such as nasopharyngeal secretion, bronchoalveolar lavage fluid, respiratory tract pathogen antibody, etc. according to the detection of pathogenic bacteria, it is further suggested that the children may have simple parapneumonic pleural effusion or empyema.

In conclusion, we found that shortness of breath and increased CRP were independent risk factors of empyema in children with parapneumonic pleural effusion.It is necessary to be aware of empyema when children with parapneumonic pleural effusion appear shortness of breath and CRP increase significantly, especially when it is more than $89.41 \mathrm{mg} / \mathrm{L}$.

\section{Declarations}

\section{Acknowledgements}

Not applicable.

\section{Funding}

This work was supported by the National Natural Science Foundation of China [Zhengrong Chen, grant number 81401296; Wei Ji, grant number 81570016].

\section{Availability of data and materials}

All data generated or analysed during this study are available from the corresponding author on reasonable request.

\section{Author contributions}


L. J. wrote the main manuscript text; W. J. and Y.W.collected and analyzed clinical data;W. J is to take responsibility for study design. All authors reviewed the manuscript.

\section{Ethics approval and consent to participate}

This study was approved by the Institutional Human Ethical Committee of Children's Hospital of Soochow University. A written consent was obtained from all the guardians who participated in this study.

\section{Competing financial interests}

Authors declare no potential conflicts of interest with respect to the authorship and publication of this article.

\section{Consent for publication}

Not applicable.

\section{References}

1. Kim J, Park JS, Cho YJ, et al. Predictors of prolonged stay in patients with community-acquired pneumonia and complicated parapneumonic effusion [J].Respirology 2016; 21:164-171.

2. Light RW. Pleural diseases. 5th ed. Philadelphia: Lippincott Williams \& Wilkins; 2007.

3. Reichert M, Hecker M, Witte B, et al. Stage-directed therapy of pleural empyema[J]. Langenbecks Arch Surg,2017,402(1):15-26.

4. Zhao moral education, Gu Lina. Identification and treatment of empyema in children [J]. Chinese Journal of Practical Pediatrics, 2017,32 (3): 168-171

5. Nath S,Thomas M,Sepncer D, et al. Has the incidence of empyema in Scottish children continued to increase beyond 2005? [J]. Arch Dis Child, 2015,100 (3):255-258.

6. Cardoso MR,Nascimento-Carvalho CM, Ferrero F, et al.Empyema and bacteremic pneumococcal pneumonia in children under five years of age[J]. J Bras Pneumol, 2014,40 (1):69-72.

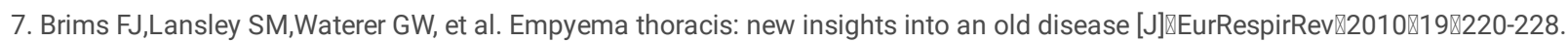

8. Alwadhi V, Dewan P, Malhotra R K, et al. Tachypnea and Other Danger Signs vs Pulse Oximetry for Prediction of Hypoxia in Severe Pneumonia/Very Severe Disease[J]. Indian Pediatr,2017,54(9):729-734.

9. Siniorakis E, Arvanitakis S, Tsitsimpikou C, et al. Acute Heart Failure in the Emergency Department: Respiratory Rate as a Risk Predictor[J]. In Vivo,2018,32(4):921-925.

10. Rialp C G, Del C B A, Perez A O, et al. Noninvasive mechanical ventilation in chronic obstructive pulmonary disease and in acute cardiogenic pulmonary edema[J]. Med Intensiva,2014,38(2):111-121.

11. Goldhill DR, McNarry AF, Mandersloot G, et al. A physiologically-based early warning score for ward patients: the association between score and outcome [J]. Anaesthesia 2005; 60: 547- 553.

12. Angurana S K, Kumar R, Singh M, et al.Pediatric empyema thoracis: What has changed over a decade?[J]. J Trop Pediatr,2019,65(3):231-239.

13. Dai Bing, Cai Xuxu. Clinical significance of pleural effusion index determination [J]. Chinese Journal of Practical Pediatrics, 2017,32 (03): $193-198$

14. Zhu Lijuan, Zhu Caiping, Yang xiaojun.the diagnostic significance of ADA, CRP and CEA in pleural effusion [J]. Journal of clinical lung, 2009, 14 (3): $313-$ 314

15. Mao Minhua, Zhang Jinshong, Jiang Juelu. Study on serum and pleural fluid C-reactive protein in the etiological diagnosis of pleural effusion [J]. Journal of clinical lung, 2015,20 (06): 1019-1021

16. Chalmers JD, Singanayagam A, Murray MP, et al. Risk factors for complicated parapneumonic effusion and empyema on presentation to hospital with community acquired pneumonia [J]. Thorax, 2009, 64(7): 592-597.

17. Krenke K,Urbankowska E,Urbankowski T,et al. Clinical characteristics of 323 children with parapneumonic pleural effusion and pleural empyema due to community-acquired pneumonia[J].J Infect Chemother,2016,22 (5):292-297.

18. Zheng Baoying, Cao Ling. Diagnosis and treatment of mycoplasma pneumonia complicated with pleural effusion in children [J]. Chinese Journal of Practical Pediatrics, 2017,32 (03): 171-174. 